\title{
Institutional specifics of IT-platforms in the management of urban water resources
}

\author{
Karine Fontana*, and Bagrat Yerznkyan \\ Central Economics and Mathematics Institute of the Russian Academy of Sciences, Nakhimovsky \\ Ave., 47, 117418 Moscow, Russia
}

\begin{abstract}
The organizational structures and institutional environment in which they operate are essential in the management of urban water resources. One of the most promising forms of such structures are information and technology platforms that ensure the functional unity of the structures and environment of the ecosystem. The effectiveness of ITplatforms largely depends on the state of the institutional environment: on the one hand, it is not easy to achieve sustainable IT-platforms, on the other hand, success in achieving the desired sustainability can lead to a state of institutional trap, when both the environment is stable and management is efficient, but the increase in water scarcity and deterioration of its quality remains. The study focuses on the need to explore management and technological aspects, based on the economy of solidarity, into a single institutional complex, i.e. the transition to intelligent water management systems. Such management systems, with extensive use of technological innovations and digital technologies, are being introduced, including within the framework of the spatial development of the Russian Federation and in the development of the strategy of socio-economic development of the country and regions.
\end{abstract}

\section{Introduction}

Water resources (WR) are of great ecological, economic and social importance. Generally, unevenly distributed, they, especially high-quality fresh water, are limited and highly volatile resources [1]. In addition, in a linear economic model, economic growth usually implies a growing demand for natural resources and an increase in waste and runoff [2]. At the same time, WR management system often fails to meet the current needs of addressing the accumulated problems in the water sector (WS), which could lead to increased water scarcity and quality, as well as to pose difficulties for food security and ecosystem protection [17].

In dealing with problems in the WS, it is important, in pursuit of sustainability, not to put a managed system into an institutional trap when, while ineffective, it will be replicated over a long period of time, thus preventing the solution of water problems [3]. To avoid this, a systemic solution of problems based on reliable information and technological innovation (TI) with a focus on linking the goals pursued with the actions of the authorities

\footnotetext{
${ }^{*}$ Corresponding author: fontana@mail.ru
} 
and all the structures concerned is needed. In other words, it is about bringing the technological and organizational aspects of WR's governance process, based on the economy of solidarity, into a single institutional integrated process.

\section{Materials and methods}

Comparative institutional analysis methods, logical and systemic methods of identifying the problems of supplying water resources (WR) to the population, production and other interested structures, as well as ensuring adequate management of them using IT-platforms, digital technologies (DT).

\section{Results and discussion}

Based on the analysis of various national and foreign management structures of WR, including IT-platforms, DT, it is concluded that the identification of institutional traps associated with WR management is ambiguous. Treated in one country as an effective institutional solution, it can lead to an institutional trap in another country. In each location where a management solution is needed, it should be linked to the entire institutional system, taking into account both the dependence of formal and informal institutions on the previous trajectory of development, and the strategic target priorities of the development of the WS and more broadly the socio-economic system of the country.

At the present stage of development, WR management cannot focus only on solving current problems, it should have a strategic vision for water sector development and the ability to implement them. A correct and comprehensive combination of tactical and strategic solutions can reduce the risks related with the acceptable supply of water of the right quality for different applications, including using alternative water supply methods, based on the principle of "what is the purpose - such is water".

It should be taken into account that the solution to the problems brewing in the WS includes both managerial and technological aspects. And TI is virtually impossible without regard to management [4]: water innovation management is crucial to stimulating TIs and overcoming the barriers that prevent their implementation, and innovation in WR management is needed to better achieve collective goals. In addition, innovation in management can be the driving force behind TI, which can stimulate their development in other sectors.

To what was said earlier about the reliability of information, let us also add its openness as a foundation for optimizing WR management both within the industry and in other sectors that use water; integration of environmental, economic, social aspects into the WR management system at the technological and methodological level. In fact, this means the reduction of the WR management process into a single institutional process of the systematic implementation of water supply, or otherwise the transition to "smart water" and intelligent management systems (IMS) of WR [5].

The concept of "smart water" has great potential, and the greatest potential lies in the Internet-of-things (IoT), Big Data, artificial intelligence (AI) and machine learning with a variety of applications, including making decisions under conditions of uncertainty aimed at reducing risk and increasing stability in the WS.

It is important to emphasize that the combined efforts of the statistical base, field observations, simulation methods, and remote satellite sensing can help to comprehensively assess the state of the WR and provide information support for the control system to achieve effective decisions. All this presupposes the integration of technologies and innovations into the IMS of WR. 
So:

- IoT deployed as part of the digitalization of the WS enables the collection of critical water-related data required for the transition to a IMS of WR. As an example, San Francisco has one of the world's largest pilot programs (178,000 units) with water meter equipped with smart sensors to record hourly water consumption; data are used to identify patterns of water consumption, detect leaks in the water supply network, etc. Another example, IoT allows to improve the efficiency of water use during irrigation: data from the local weather station and soil moisture sensors are transmitted to the irrigation system control unit to optimize / reprogram the irrigation mode in automatic and/or real time mode.

- Big Data applications [6], analysing large amounts of data, allow to discover hidden patterns and correlations associated with water, extracting useful information for decision-making; integrate water data with other related data, generating a broader understanding of the evolution of processes affecting WR, which ultimately contributes to better WR management.

- Various methods, models and algorithms of machine learning based on AI can be used in the IMS of WR, in particular, in predicting water quality and identifying pollution sources [7]; analysis of the efficiency of water use [8]; forecasting various desalination technologies [9]; aquifer management [10], etc. Advances in AI and machine learning methods can complement satellite and ground-based observations in WR monitoring, thereby providing decision support in the IMS of WR.

The foreign experience of IMS of WR with the use of DT and TI is diverse:

1. The innovative platform SANePLAN [11], which is an interactive information resource and implemented in a number of cities in Italy and Spain, is aimed at comprehensively addressing issues in the management of urban WR using TI and DT. Among other things, Big Data applications are integrated into the structure of the platform (for collecting and processing a large array of data, including the environmental situation in the city). This resource provides local authorities and interested users with information on urban water infrastructure (including water leaks); analyses the efficiency of drinking water use; processes data on the volumes of collected and treated urban wastewater; evaluates the impact of decisions made in the WS on the environmental situation in the city. This platform allows the exchange of data between authorities, which contributes to the implementation of the principles of openness and accessibility of information for all stakeholders. Moreover, SANePLAN allows to simulate the situation of the state of urban WR in the implementation of specific management decisions and urban projects [12].

2. "Atlas of Urban Waters for Europe" (Blue Cities Project) [13] enables cities to assess actions to achieve the goal of "Water-Wise City" based on the experience and best practices of management of more than 40 cities in Europe. Two online tools are used to present its interface in an innovative format. One of them, City Blueprint, is an interactive strategic decision support tool that allows, based on an analysis of various management aspects, to provide an overview of the strengths and weaknesses of the WR management system, providing specific options for improving the sustainability of the city's water supply networks. Another tool, City Amberprint, is used to assess the city's progress, including in the area of IT and the achievement of the Water-Wise City goal, taking into account the environmental impact, quality of life index and risks. These assessments can be used to analyse the current situation and prioritize management decisions regarding urban water resources, as well as inform decision-makers and other stakeholders about the current water situation in the city [14].

3. The interactive IT-platform Environmental Glance is used by the OECD as a tool for monitoring, assessing environmental progress (including in relation to WR) and tracking the path towards sustainable development. The platform provides interactive access to environmental data obtained from OECD members, as well as collected from international 
sources; has a flexible structure that allows it to adapt to changing conditions, goals and objectives [2].

As for Russia, the large-scale spatial development program proposed by the President (March 2018 message to the Federal Assembly) assumes the widespread use of TI, DT and modern approaches in housing and communal services in developing a strategy for socioeconomic development. In modern conditions, there is a gradual transition to IMS with an emphasis on advanced technological solutions and digitalization of control systems to ensure effective solutions to current processes and emerging problems, also thanks to the involvement of citizens, businesses and authorities [15]. At the same time, the introduction of DT in management should not be implemented according to the same scheme without taking into account local realities and economic opportunities of the city/region. At least 3 approaches can be distinguished: a decentralized model of the transition to DT in management (suitable, for example, for large cities where the "smart city" process has already been launched, there are financial opportunities, as well as interested business and technological players); centralized model (suitable for large and medium-sized cities, which first of all require resource assistance for the transition to IMS); for small and mediumsized cities, the transition to DT in management at this stage is possible for individual sectors - a "model of local actions" - with the cooperation of large business and technology players with local authorities (for more details, see [15]).

Of high relevance in the introduction of IMS of WR is the improvement of the regulatory and legal framework (which, among other things, contributed to the development and implementation of TI in various spheres of life and protected the interests of intellectual property) and the implementation of institutional changes (to consolidate the priorities of digital transformation in the strategies of socio-economic development of territories).

An example of the implementation of IT-platforms that ensure the transition to the IMS of WR is the Federal project "Digital Ob-Irtysh Basin" [16] (within the framework of the implementation of the national projects of the Russian Federation "Ecology", "Science", "Education" and the program "Digital Economy of the Russian Federation"), the purpose of which is to create a control system for the WR of the largest river basin in Russia, based on Big Data using the technology of "Smart Digital Twins" (SDT). This is about the creation of a "techno-natural facility with the identification of critical factors of technogenic load and the formation of a matrix of critical parameters and constraints" (Federal Program "Digital Ob-Irtysh Basin." Official site of Centre of National Technological Initiative "New Manufacturing Technologies" on the basis of the Institute of Advanced Manufacturing Technologies of Peter the Great St. Petersburg Polytechnic University (NTI SPbPU Centre) [17], with a convenient digital WR control system, which has a high degree of adequacy to the WR state and includes intelligent DT with various functional and interfaces. This toolkit will make it possible to switch to predictive digital modelling of the state of WR and create a unified national IMS of WR, allowing to take rapid decisions at different levels of government in the face of uncertainty and risks in the WS.

As part of the project, it is planned to create the first "digital factory" in Russia to collect data and upload it to the federal IoT platform created by the Ministry of Digital Industry. To "fill" the system, it is planned to use data from ground measuring complexes, unmanned aerial vehicles and space equipment, all online. Methods of mathematical modelling and SDT are used to process the data array (including cleaning from information "garbage") and sorting information, taking into account the requirements of different interested structures; and the use of AI will make it possible to obtain possible options for management trajectories in decision-making. Thus, federal structures and executive authorities will have an objective picture of the state of WR in real time and possible prospects for the development of the situation when making certain managerial decisions. 
The advantages of the project are also that it has, among other things, a socio-economic effect, the architecture of the platform allows you to systematically solve also other tasks, such as creating new competencies in the region, jobs, introducing technological innovations, solving import substitution issues.

And yet, despite such initiatives, digitalization in Russia is proceeding slowly. In particular, the director of Housing and Communal Services Development Department of the Ministry of Construction of the Russian Federation S.V. Nikonova, at the All-Russian Water Congress-2020 noted that not only numerous violations of the rules for the protection of water bodies contribute to the pollution of WR, but also ineffective state monitoring and environmental control due to the slow introduction of DT and TI, and the lack of objective information on the state of water bodies hinders the technological and economic development of the sphere, complicates the adoption of management decisions and the transition to "smart water".

\section{Conclusions}

1. Problems of water supply, both current and strategic, should be solved systematically, without scattering them in time, focusing both on ensuring public and environmental wellbeing, and on linking water problems with sustainable development policies.

2. It is important to understand that an effective institutional solution, when replied, can lead to an institutional trap. Therefore, in each individual case, it is necessary to have its own, linked to the entire specific institutional system, management solution based on TI and DT.

3. Scientific research and advanced TI, DT should form the basis for building an effective policy of the state, practicing focus on coordinating goals and actions to achieve them, and contribute to the transition to IMS of WR, at all levels of executive power and with respect for the inclusiveness of all stakeholders.

4. Barriers to achieving the objectives are often: limited institutional capacity, financial constraints, lack of understanding of the economic value of water, incentives for the introduction of TI.

5. Particular attention should be paid to the provision of comprehensive and reliable information on the state of WR, the deficit of which can become a limiting factor for effective management decisions, and for the transition to "smart water" and sustainable development.

6. The solution to the urgent problems in the WS includes both managerial and technological aspects, which mutually complement each other. To implement the currently relevant concept of "smart water", is needed to pay attention to the experience of ITplatforms that have demonstrated great capabilities, such as: IoT, Big Data, AI and machine learning with a variety of applications. At the same time, it is important to provide protection against the risks of falling into an institutional trap.

7. It seems relevant to move to an IMS of WR based on multi-body information platforms that monitor the quality and quantity of WR (using mathematical modelling methods) and manage data. It is important to replenish such platforms with data from the water cycle and other interrelated domains (with the integration of water with environmental, economic, social aspects), as well as to conduct targeted monitoring and analysis of drinking and wastewater to justify decisions.

8. The particular importance on the way to the IMS has the improvement of the institutional system - both formal (normative legal acts of regulation and stimulation of technological solutions) and informal (taking into account the realities that are difficult to formalize and can protect from institutional traps). Together, both of these components 
contribute to the consolidation of the priorities of digital transformation in the strategies of socio-economic development.

9. The research results are of not only of scientific, but also of practical interest: they can be used by state and municipal authorities, all legal entities and individuals related to the WR management system. We hope that the study will contribute to the discussion about the problems in the WS, about the need to take measures for the transition to intelligent WR management using TI and DT in order to achieve the goals of sustainable development.

\section{References}

1. OECD. OECD Environmental Outlook to 2050 (OECD Publishing 2012)

2. OECD. Environment at a Glance 2020 (OECD Publishing, Paris 2020)

3. V.M. Polterovich, Economics and Mathematical Methods, 35 (2) (1999)

4. European Innovation Partnership, Water Strategic Implementation Plan (Brussels, 2012) https://www.eip-water.eu/

5. B.A. Erznkyan, K.A. Fontana, CEMI Bulletin, 2 (2018) http://cemi.jes.su/

6. United Nations (UN), World Water Development Report 2020: Water and Climate Change, Paris, UNESCO (2020)

7. S. Srivasta, S. Vaddadi, and S. Sadistap, Applied Water Science, 8 (130) (2018)

8. Y. Chen, J. Li, W. Ju, H. Ruan, Z. Qin, Y. Huang, N. Jeelani, J. Padarian, and P. Propastin, PLOS One, 7, e0179875 (2017)

9. P. Cabrera, J.A. Carta, J. González, G. and Melián, Desalination, 15, 140 (2017)

10. M. Moazamnia, Y. Hassanzadeh, A.A. Nadiri, R. Khatibi, S. Sadeghfam, Journal of Hydrology, 571, 765 (2019)

11. J. L. S. Seoane, 10th Meeting of the OECD Water Governance Initiative. Draft Agenda. Vienna, Austria, SANePLAN: Integrating Sanitation and Urban Planning, Fundación Instituto Tecnológico de Galicia (2017)

12. B.A. Erznkyan, K.A. Fontana, Strategic planning and development of enterprises: materials of the Nineteenth All-Russian Symposium, 55 (2018)

13. Urban Water Atlas for Europe. EU publications: Joint Research Center (European Commission), 168 (2018)

14. K.A. Fontana, B.A. Erznkyan, Bulletin of the Kemerovo State University. Series: Political, Sociological and Economic Sciences, 4, 157 (2018)

15. D. Titov, Economy and Life, 25, 9771 (2018) https://www.eg-online.ru

16. Federal project "Digital Ob-Irtysh Basin", Main technological partner - State Company «Rostec») https://nticenter.spbstu.ru/

17. OECD Principles on Water Governance, Organisation for Economic Co-operation and Development (OECD Publishing: Paris, France, 2015) http://www.oecd.org/ 